Darauf folgt der Vortrag:

\title{
Eine Reaktion zur Erkennung und Unterscheidung von Kunsthonigen und Naturhonigen.
}

\author{
Von
}

Dr. J. Fiehe in Stralaburg.

Von der theoretischen Erwägung ausgehend, daß der Kunsthonigfabrikant mit ganz anderen, ich möchte sagen, gröberen Mitteln arbeitet, um das Produkt der Biene, den Honig, nachzumachèn, möchte ich Sie auf eine Reaktion aufmerksam machen, welche durch die Fabrikation der Kunsthonige selbst bedingt wird. Wenngleich diese Reaktion keine endgültige Lösung der Kunsthonigfrage bedeuten soll, so hoffe ich doch, $\mathrm{da} \beta$ sie dazu beitragen wird und vielleicht den Anstoß gibt zu weiteren Untersuchungen in dieser Hinsicht, die ich leider bisher nicht ausführen konnte.

Die Fragen, die icb mir bei Beginn meiner Untersuchungen vorlegte, waren etwa folgende: Unter welchen Bedingungen arbeitet die Biene bei Bereitung des Honigs und unter welchen der Fabrikant bei Herstellung seines Kunstproduktes? Enthält der Kunsthonig Körper, welche in keinem Naturhonig enthalten sein können? Bedingt die normale Herstellung der Kunsthonige die Gegenwart solcher Körper?

Die Beantwortung dieser Fragen war nach meinen Erwägungen etwa folgende: Die Biene sammelt fertig gebildeten Invertzucker der Blüte und invertiert etwa vorhandene Saccharose mit Hilfe von Enzymen. Eine völlige Aufklärung der Arbeiten der Biene ist bisher nicht erfolgt, doch ist es wahrscheinlich, daß die Enzyme die Spaltung der Saccharose bewirken und die Säuren mehr einen konservierenden oder einen anderen $Z$ week erfüllen. Alle diese Arbeiten nimmt die Biene bei nicht wesentlich erhöhter Temperatur (Körpertemperatur) vor. Dieses alles ist darum wichtig, weil der Kunsthonigfabrikant unter ganz anderen Versuchsbedingungen arbeitet. Er invertiert Rübenzucker mit Hilfe von Säuren bei bedeutend erböhter Temperatur.

Aus der Literatur ${ }^{1}$ ) ist nun ersichtlich, dab die Fruktose durch Säuren leicht zersetzt wird. Es gibt zwar Inversionsmethoden, welche die Herstellung eines fast reinen, von Zersetzungsprodukten freien Invertzuckers ermöglichen, doch diese werden nach meinen Erfahrungen bei der Herstellung der Kunsthonige bisher nicht angewendet. Es liegt auch gar nicht im Interesse des Kunsthonigfabrikanten, einen völlig reinen Invertzucker herzustellen, sondern viel eher einen solchen, der einen größeren Gehalt an Nichtzucker aufzuweisen hat, wegen der Bedeutung, welche dem Nichtzucker bei Beurteilung der Honige von unserer Seite aus beigelegt wird.

Aus diesen Erwägungen ergibt sich, daß die Kunsthonige wahrscheinlich Zersetzungsprodukte der Fruktose aufweisen werden, die in keinem Naturbonig enthalten sein können und dürfen. Der Nachweis dieser Zersetzungsprodukte mulite also anch naturgemäß einen Nachweis der Kunsthonige ermöglichen.

1) Vergl. Lippmann, Chemie der Zuckerarten, S. 900-912. 
Diese rein theoretische Folgerung hat sich in der Tat bewahrheitet. Die Kunsthonige, welche mir zur Verfügung standen, und zwar solche bester wie schlechtester Qualität, besitzen in mehr oder minder großer Menge derartige Zersetzungsprodukte. der Fruktose.

Der Nachweis dieser Körper kann leicht in folgender Weise ausgeführt werden:

Einige Gramm Honig werden im Mörser mit etwas Äther verrieben und der Äther wird in ein kleines Porzellanschälchen abfiltriert. Der völlig trockene Rückstand wird mit einigen Tropfen einer Resorcin-Salzsäure befeuchtet $(1,0 \mathrm{~g}$ Resorcin auf $100 \mathrm{~g}$ rauchende konzentr. Salzsäure vom spez. Gew. 1,19). Bei Gegenwart von Zersetzungsprodukten tritt eine orangerote Färbung auf, welche rasch in Kirschrot und dann in Braunrot übergeht, Die Färbung ist sehr intensiv und nicht zu verkenrien. Naturhonige geben diese Reaktion nicht. In der Literatur finden wir eine Reaktion auf Saccharose von B. Rayma ${ }^{1}$ ) angegeben, die darin besteht, daß man Zucker mit Resorcin-Salzsäure kocht, wodurch dann eine Rotfärbung entsteht. Diese Färbung wird den durch die konz. Salzsäure sich bildenden Huminsubstanzen zugeschrieben. In der von mir ausgeführten Art und Anwendung ist die Reaktion neu. Sie ist außerordentlich empfindlich und vermag auch einen geringen Zusatz von Kunsthonig zu Naturhonig nachzuweisen.

Bei meinen Untersuchungen beobachtete ich auch bei zweifellos echten Honigen minimale, raseh verschwindende rosa bis orangerote Färbungen, die ich nicht unerwähnt lassen möchte, um von vornherein Irrtümer nach dieser Richtung hin anszuschließen. Diese Reaktion ist darauf zurückzuführen, daß die Fruktose in Äther nicht völlig unlöslich ist. Behandelt man nun den Ätherrückstand mit Resorcin-Salzsäure, so tritt momentan eine Zersetzung der minimalen Fruktosemengen und deshalb eine schwache Färbung ein. Eine Verwechselung dieser normalen Reaktion mit der auf Kunsthonig ist aber, wie die Praxis beweist, nicht gut möglich.

Die Übertragung der Reaktion auf Invertzucker des Handels hatte ebenfalls verhältnismäßig günstige Ergebnisse. Leider standen mir bisher nur wenige Invertzucker zur Verfügung, duch reagierten sie prompt; die fast reinen Invertzucker natürlich viel schwächer, wie die von geringerer Qualität. Letztere kommen aber für Fälschungen wohl ausschließlich in Betracht.

Von Kunsthonigen wurden die bekanntesten Handelsmarken, etwa 20 an der Zahl, soweit jch sie erhalten konnte, untersucht. Die Aufzählung der Marken unterlasse ich wegen der Kürze der Zeit. An echten Honigen standen mir etwa 50 Proben aus Deutschland und Mexiko zur Verfügung. Südfranzösische Honige aus der Umgegend von Narbonne sind von mir ebenfalls in größerer Anzahl untersucht worden.

Inzwischen erbielt ich mehrere wertvolle Bestätigungen meiner Angaben und zwar von Seiten, welche sich angelegentlich mit ihrer Nachprüfung beschäftigt haben.

Es liegt zwar in der Natur der neuen Reaktion begründet, daß es Kunstprodukte geben kann, die nicht in der angegebenen Weise reagieren, doch diese sind jedenfalls bisher nur in verschwindend geringer Anzahl auf dem Markte vertreten.

\section{Diskussion:}

Der Vorsitzende ist der Ansicht, daß die Reaktion tatsăchlich auf wissenschaftlicher Grundlage beruhe.

1) Listy chem. 1887, 11, 161; Chem. Zentralblatt 1887, 621-622. 
Dr. von $R$ a umer führt aus, daß mit organischen Säuren hergestellter Invertzucker die Reaktion nicht gebe. Die Reaktion trete nicht immer ein. Bei Mischungen von Honig und Kunsthonig entständen Mischfarben. Mit Lävulinsäure trete die Reaktion manchmal ein und manchmal nicht. nie ein.

Dr. J ackenack hat mit der Reaktion gute Erfolge gehabt; bei Naturhonig trat sie

Dr. Fiehe betont, daß die Reaktion mit reiner Lävulinsäure nicht eintritt. Naturhonig könne die Reaktion nicht geben.

Der Vorsitzende betont, dak die Reaktion mit Lävulinsäure nichts zu tun habe.

Dr. Reese hat beobachtet, dak die Reaktion bei reinem Honig nie, wohl aber bei Kunsthonig eintritt. Invertzucker und sogen. Nektarin gaben die Reaktion nicht.

Dr. Röhrig hebt hervor, dafes aufser der Ley'schen und F' i e h e'schen Reaktion noch andere Verfahren zur Unterscheidung von Honig und Kunsthonig gebe. Er weist auf das häufige Vorkommen von Weinsäure in Kunsthonig hin, die an bestimmten Reaktionen zu erkennen sei, ferner darauf, daß Kansthonig in der Regel in knpfernen Kesseln zubereitet werde und dafs dadurch die Ware kupferhaltig werde. Es sei wohl anzunehmen, dafis echter Honig niemals Kupfer enthalte.

Es folgt die Verhandlung:

\section{Über die Kennzeichnung von Marmeladen, Fruchtsäften und anderen Obstkonserven.}

Bericht über die gemeinschaftliche Beratung von Mitgliedern der Freien Vereinigung Deutscher Nahrungsmittelchemiker mit Vertretern der Industrie.

Berichterstatter: Dr. A. Beythien-Dresden.

Hierzu sind folgende beiden Vorlagen vorhanden :

\section{Ergebnisse der Besprechang mit den Vertretern der Industrie, betreffend Beurteilnng der Obsterzengnisse \\ in Frankfurt a. M, am 7. Dezember 1907.}

1. Als Grundlage für die Beurteilung eines Nahrungsmittels gilt die normale Besehaffenheit. Abweichungen von dieser Beschaffenheit werden als zulässig erachtet, sofern sie richtig deklariert und die Zusätze nicht gesundheitsschädlich oder wertlos sind.

2. Seitens des Vereins Deutscher Fruchtsaftpresser wurde die Frage des Zusatzes von Konservierungsmitteln angeregt. Die Versammlang beschließst, diese Frăge aus der Beratung auszuschliefen.

3. Gelees und Marmeladen sind als Eunstgelee und Kunstmarmelade zu bezeichnen, wenn ihr Gehalt an Fruchtbestandteilen, bezogen auf das fertige Produkt, nicht mindestens $20 \%$ des fertigen Produktes an frischer Frucht entspricht.

4. Die beim Einkochen eines Obsterzeugnisses entweichenden und wiedergewonnenen Stoffe dürfen diesem Produkte wieder zugesetzt werden, ohne daß Deklaration nötig ist.

5. Die Vertreter der Industrie erklären sich bereit, bei Obsterzeugnissen mit mehr als $30 \%$ Stärkesirup im fertigen Produkt die Deklaration "mit mehr als 30\% Stärkesirup" anzuwenden. Die Voranssetzung für die Feststellung einer Grenzzahl ist die Annahme einer einheitlichen Methode und der Festsetzung ihrer Fehlergrenzen seitens der Freien Vereinigung Deutscher Nahrungsnittelchemiker. 